\section{Kidney \\ Blood Pressure Research}

Kidney Blood Press Res 2016;41:604-613

DOI: 10.1159/000447929

Published online: September 01, 2016

Accepted: July 19, 2016

This article is licensed under the Creative Commons Attribution-NonCommercial-NoDerivatives 4.0 International License (CC BY-NC-ND) (http://www.karger.com/Services/OpenAccessLicense). Usage and distribution for commercial purposes as well as any distribution of modified material requires written permission.

\title{
The Influence of Thyroid Function, Inflam- mation, and Obesity on Risk Prediction of Acute Kidney Injury by Cystatin $C$ in the Emergency Department
}

\author{
Moritz Schanz ${ }^{\mathrm{a}}$ Dirk Pannes ${ }^{\mathrm{a}} \quad$ Jürgen Dippon ${ }^{\mathrm{b}} \quad$ Christoph Wasser $^{\mathrm{a}}$ \\ Mark Dominik Alscher ${ }^{a} \quad$ Martin Kimmela \\ aDepartment of Internal Medicine, Division of General Internal Medicine and Nephrology, Robert-Bosch

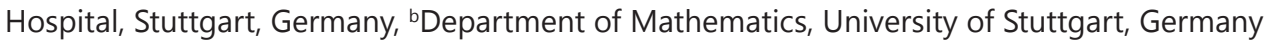

\section{Key Words}

Acute kidney injury - Emergency department - Cystatin C - Thyroid function - C-reactive protein $•$ Body mass index

\begin{abstract}
Background/Aims: There is a growing role for emergency departments (ED) in assessing acute kidney injury (AKI) for hospital admissions but there are few studies addressing acute kidney injury biomarkers and confounding factors in the ED. Cystatin $\mathrm{C}(\mathrm{Cys} C)$, a newer renal biomarker, is influenced by thyroid function, inflammation and obesity. This study aims to be the first study to address the impact of these parameters in the ED. Methods: Admitted patients ( $n=397)$ were enrolled in the ED at Robert-Bosch-Hospital, Stuttgart, Germany. Daily serum creatinine $(\mathrm{s} C r)$ was recorded for AKI classification by Kidney Diseases Improves Global Outcome (KDIGO) criteria. CysC, thyroid stimulating hormone (TSH), thyroxine (T4), C-reactive protein (CRP) and body mass index (BMI) were registered at enrollment in the ED. Serum samples were collected at enrollment, after 6 hours and in the following mornings (day 1 to day 3). The correlation of $\mathrm{Cys} C$ and $\mathrm{sCr}$ was studied on a two variable logistic regression model. A linear predictor was computed to predict minimal AKI stage and area under the curve (AUC) was calculated. Results: Of 397 patients enrolled for classification by KDIGO AKI criteria, $\mathrm{n}=152$ (38\%) developed AKI, $\mathrm{n}=69$ (17.4\%) reached AKI stage I, $\mathrm{n}=70$ (17.6\%) AKI stage II, and $n=13$ (3\%) AKI stage III. Although a correlation between CRP and CysC levels was shown (rho=0.376), this didn't affect the predictive ability for AKI according to our data. We compared receiver operating characteristic (ROC) curves (DeLong test) of CysC to ROC curves of Cys $\mathrm{C}$ with the additional variables TSH, BMI, and CRP respectively. Our data shows that addition of $\mathrm{CRP}, \mathrm{TSH}$, or BMI does not improve prediction of AKI stage beyond prediction
\end{abstract}




\section{Kidney \\ Blood Pressure Research}

based solely on CysC levels. Conclusions: CysC is known to be influenced by thyroid function, inflammation and obesity, but in our large ED population there was no significant impact of these factors on the diagnostic accuracy of CysC to detect AKI in ED patients.

(C) 2016 The Author(s)

Published by S. Karger AG, Basel

\section{Introduction}

Acute kidney injury (AKI) is a common syndrome, but is still related to increased mortality, heavy burden of illness and high costs [1-5]. The importance of emergency departments (ED) for hospital admissions is rising [6] but few studies address acute kidney injury (AKI) in the ED [7-12]. Recently it was reported that AKI in the ED is more common than previously thought with $25 \%$ of unselected ED patients affected [10].

In the last decade, an AKI classification system was proposed by the Acute Dialysis Quality Initiative (ADQI) and validated in large patient cohorts [2]. Now referred to as the Kidney Diseases Improves Global Outcome (KDIGO) criteria, this system classifies AKI into three stages (stage 1-3; mild, moderate, severe) based on increases in serum creatinine ( $\mathrm{sCr}$ ) and a decrease in urinary output, which is an independent indicator of loss of kidney function [13].

Cystatin $\mathrm{C}(\mathrm{CysC})$ is one of the most promising renal biomarkers. CysC is freely filtered at the glomerulus, and is neither secreted nor reabsorbed by renal tubules [14]. CysC is produced by all nucleated cells in the human body at a fairly constant rate [15]. This characteristic makes CysC useful for detection of AKI, but there are several known limitations: CysC is influenced by thyroid function, inflammation and obesity $[16,17]$.

We previously reported on the performance of tissue inhibitor of metalloproteinase-2, insulin-like growth factor binding protein-7 [TIMP-2]-[IGFBP7] for risk assessment of AKI in patients presenting to the ED [18]. In this subanalysis of our ED cohort, we examined the impact of thyroid function, inflammation and obesity on the performance of CysC in a nonintensive care unit (ICU) cohort of patients who presented to the ED.

\section{Materials and Methods}

\section{Study Design and Subjects}

Patients presenting to the ED of the Robert Bosch Hospital (Stuttgart, Germany) were screened during initial diagnostic workup. Inclusion criteria were age $\geq 18$ years, willingness to participate indicated by signing for informed consent, admission to the internal medicine service of the hospital, and hemoglobin $\geq 9.5 \mathrm{~g} / \mathrm{dl}$ (women) or $\geq 10.5 \mathrm{~g} / \mathrm{dl}$ (men). Exclusion criteria were: a dialysis requirement (stage 5D of chronic kidney disease according to Kidney Disease Outcomes Quality Initiative, KDOQI), pregnancy, or failure to meet any of the inclusion criteria. Enrolled patients received a physical examination, a medical history and samples for routine laboratory investigation. Urine output, serum samples were collected at enrollment, after 6 hours and in the following mornings. CysC was measured by nephelometry. All relevant clinical data, including patient demographics, health history, reason for hospital admission and baseline $\mathrm{sCr}$ were collected in case report forms as anonymized data.

The study was approved by the Ethics Committee of the University of Tuebingen and all subjects provided written informed consent.

\section{Clinical Endpoints}

AKI status within 48 hours after enrollment was classified according to the KDIGO consensus guideline. A pre-hospital baseline $\mathrm{sCr}$ value was obtained whenever possible from the primary care physician. If a baseline $\mathrm{sCr}$ was not available, the lowest $\mathrm{sCr}$ from the hospital stay was used as the reference value for 


\section{Kidney Blood Pressure Research}

KDIGO staging [19]. The primary endpoint was AKI stage 1-3. Adjudication of AKI was performed by a nephrologist.

\section{Statistical Analysis}

Correlations of continuous variables were investigated by scatter plots, by non-parametric scatter plot smoothers, and by Spearman's rank correlation coefficient rho. If measurements showed a heavily skewed distribution, logarithms of the measurements were taken.

To evaluate the predictive power of a variable, logistic regression models were fitted to the data. Instead of considering models with ordinal outcome (AKI stage with levels "No AKI", "Stage I", "Stage II" and "Stage III") we considered several binary outcomes. Binary logistic regression models supply linear predictors, defined as one and two variables, which may serve as a score to predict AKI stage. For each individual these scores were compared with the observed binary outcome by computing the receiver operating characteristic (ROC) curves and their related area under the curve (AUC). ROC curves based on scores defined as binary variables were finally compared using the method of DeLong et al. [20]. In addition, we report $p$-values related to each independent variable in the two-variable logistic regression model (Wald's statistic). To compare one- and two-variable logistic regression models, $p$-values related to the deviance statistic are computed. If $p$-values do not exceed 0.05 , findings are considered to be statistically significant.

We performed the same analysis in an additional subgroup of patients with known chronic kidney disease (CKD).

For all statistical computations and figures the statistical environment R (Vienna, Austria), Version 3.2.2, and several add-on libraries (pROC, RColorBrewer) are used [21].

\section{Results}

\section{Baseline Characteristics and AKI Endpoint}

We enrolled 400 patients, of whom three refused or withdrew consent. AKI stage within 48 hours was assessed for all 397 patients for classification by KDIGO AKI criteria, and $n=152$ (38\%) developed AKI: stage I (risk) $n=69$ (17.4\%), stage II (injury) $n=70$ (17.6\%) and stage III (failure) $n=13$ (3\%) (Fig. 1).

Baseline parameters (Table 1A, and 1B) significantly associated with the primary endpoint (AKI stage 1-3) include enrollment sCr and plasma CysC. The most common comorbidities were hypertension (60\%), infectious disease (24\%), diabetes (24\%), heart failure (23\%) and myocardial infarction/acute coronary syndrome (21\%). A history of chronic kidney disease was present in $12 \%$ of the cohort. Significant differences between patients with or without AKI were shown in admission sCr, admission CysC, and admission urea. Furthermore, significant differences in CRP levels, leukocytes, hemoglobin, hematocrit and chloride were remarkable. In the AKI cohort significantly more patients had comorbid hypertension.

\section{Influence of Thyroid Function, Inflammation and BMI in AKI}

First, we examined the correlation between sCr and CysC levels. As expected, a significant correlation was shown between those two kidney markers (rho=0.697), summarized by a scatter plot smoother and Spearman's rank correlation coefficient (Fig. 2).

Second, we analyzed the association of CRP, BMI and TSH measures with CysC (Fig.3, a-c). Besides BMI, each quantity is displayed on a logarithmic scale. CRP correlates with increasing CysC levels (rho=0.376).

Third, we investigated whether CRP, TSH or BMI levels improve prediction of AKI stage (Table 2 and Fig. 4). The ROC curves using CysC to predict a minimal AKI stage "risk", "injury" or "failure", showed a AUC of $0.7,0.74$ and 0.8 respectively. A significant correlation between the logarithmic CysC and AKI stage was detectable $(p<0.0001)$. Log(CRP) levels showed a significant association with AKI stage "risk" and "injury" ( $p=0.00073$ and $p=0.011$ respectively), whereas $\log (\mathrm{TSH})$ and BMI showed no significant association with any AKI stage ( $p>0.05)$. 


\section{Kidney Bloód Pressure Research}

Table 1A. Baseline characteristics; BMI: Body mass index; CysC: Serum Cystatin C; Hb: Hemoglobin; Hct: Hematocrit; ICU: Intensive care unit; IMC: intermediate care unit; IQR: Interquartile range; sCr: Serum Creatinine.

\begin{tabular}{|c|c|c|c|c|c|c|c|c|c|c|c|c|c|c|c|c|c|}
\hline & AKIN 0 & & & AKIN 1-3 & & & & & & & & & & & & & \\
\hline & & & & Tolal & & & & AKIN 1 & & & & IN 2 & & & AKIN 3 & & \\
\hline & $\mathrm{n}(\%)$ & Median & IQR & $\mathrm{n}(\%)$ & Median & IQR & $p$-value & $\mathrm{n}(\%)$ & Median & IQR & $\mathrm{n}(\%)$ & Median & IQR & $\mathrm{n}(\%)$ & Median & IQR & $\begin{array}{l}\text { Total } \\
\mathrm{n}(\%)\end{array}$ \\
\hline $\begin{array}{l}\text { Total } \\
\text { General ward } \\
\text { MCC } \\
\text { ICU }\end{array}$ & $\begin{array}{l}245(62 \%) \\
186(76 \%) \\
50(20 \%) \\
9(4 \%)\end{array}$ & & & $\begin{array}{l}152(38 \%) \\
109(72 \%) \\
35(23 \%) \\
8(5 \%)\end{array}$ & & & & $\begin{array}{l}69(17 \%) \\
51(74 \%) \\
16(23 \%) \\
2(3 \%)\end{array}$ & & & $\begin{array}{l}70(18 \%) \\
48(69 \%) \\
17(24 \%) \\
5(7 \%)\end{array}$ & & & $\begin{array}{l}13(3 \% \%) \\
10(77 \%) \\
2(15 \%) \\
1(8 \%)\end{array}$ & & & $\begin{array}{l}397 \\
295(74 \%) \\
85(22 \%) \\
17(4 \%)\end{array}$ \\
\hline $\begin{array}{l}\text { Age (years) } \\
\text { BMI }\left(\mathrm{kg} / \mathrm{m}^{2}\right)\end{array}$ & & $\begin{array}{l}62.0 \\
26.7\end{array}$ & $\begin{array}{l}23.0 \\
6.0\end{array}$ & & $\begin{array}{l}71.0 \\
27.7\end{array}$ & $\begin{array}{l}15.3 \\
5.9\end{array}$ & $\begin{array}{l}<0.0001^{*} \\
0.08\end{array}$ & & $\begin{array}{l}70.0 \\
27.7\end{array}$ & $\begin{array}{l}13.0 \\
5.8\end{array}$ & & $\begin{array}{l}71.5 \\
27.7\end{array}$ & $\begin{array}{l}15.8 \\
6.1\end{array}$ & & $\begin{array}{l}66.0 \\
28.4\end{array}$ & $\begin{array}{l}39.0 \\
5.7\end{array}$ & \\
\hline $\begin{array}{l}\text { Admission } \mathrm{sCr}(\mathrm{mg} / \mathrm{dL}) \\
\text { Admission CysC (mg/al) } \\
\text { Admission Urea (mg/LI) }\end{array}$ & & $\begin{array}{l}0.9 \\
0.9 \\
30.0\end{array}$ & $\begin{array}{l}0.3 \\
0.3 \\
16.0\end{array}$ & & $\begin{array}{l}1.1 \\
1.4 \\
42.0\end{array}$ & $\begin{array}{l}0.7 \\
0.7 \\
37.3\end{array}$ & $\begin{array}{l}0.0001^{*} \\
<0.0001^{*} \\
0.0001^{*}\end{array}$ & & $\begin{array}{l}1.1 \\
1.3 \\
42.0\end{array}$ & $\begin{array}{l}0.6 \\
0.6 \\
28.0\end{array}$ & & $\begin{array}{l}1.1 \\
1.3 \\
40.5\end{array}$ & $\begin{array}{l}0.7 \\
0.6 \\
29.0\end{array}$ & & $\begin{array}{l}3.5 \\
2.2 \\
100.0\end{array}$ & $\begin{array}{l}3.6 \\
1.8 \\
52.0\end{array}$ & \\
\hline $\begin{array}{l}\text { 6h sCr (mg/dL) } \\
\text { Day } 1 \mathrm{sCr}(\mathrm{mg} / \mathrm{dL}) \\
\text { Day } 2 \mathrm{srC}(\mathrm{mg} / \mathrm{dL}) \\
6 \mathrm{hCysC}(\mathrm{mg} / \mathrm{dL}) \\
\text { Day } 1 \mathrm{CyyC}(\mathrm{mg} / \mathrm{dL}) \\
\text { Day } 2 \mathrm{CysC}(\mathrm{mg} / \mathrm{dL})\end{array}$ & & $\begin{array}{l}0.9 \\
0.9 \\
0.9 \\
1.0 \\
1.0 \\
1.0\end{array}$ & $\begin{array}{l}0.3 \\
0.3 \\
0.3 \\
0.3 \\
0.4 \\
0.4\end{array}$ & & $\begin{array}{l}1.1 \\
1.1 \\
1.2 \\
1.4 \\
1.5 \\
1.5\end{array}$ & $\begin{array}{l}0.7 \\
0.7 \\
0.7 \\
0.7 \\
0.9 \\
0.8\end{array}$ & $\begin{array}{l}<0.0001^{*} \\
<0.0001^{*} \\
<0.0001^{*} \\
<.0001^{*} \\
<0.0001^{*} \\
0.0001^{*}\end{array}$ & & $\begin{array}{l}1.0 \\
1.1 \\
1.2 \\
1.4 \\
1.5 \\
1.4\end{array}$ & $\begin{array}{l}0.5 \\
0.6 \\
0.6 \\
0.6 \\
0.6 \\
0.7\end{array}$ & & $\begin{array}{l}1.0 \\
1.1 \\
1.1 \\
1.4 \\
1.5 \\
1.5\end{array}$ & $\begin{array}{l}0.7 \\
0.6 \\
0.4 \\
0.6 \\
0.8 \\
0.8\end{array}$ & & $\begin{array}{l}2.7 \\
3.0 \\
2.4 \\
2.8 \\
2.8 \\
2.2\end{array}$ & $\begin{array}{l}2.3 \\
3.3 \\
3.4 \\
1.4 \\
2.2 \\
1.7\end{array}$ & \\
\hline $\begin{array}{l}\text { Urine Output } \mathrm{hm}(\mathrm{mL} / \mathrm{kg} / \mathrm{h}) \\
\text { Urine Oupput Day } 1(\mathrm{~mL} / \mathrm{kg} / \mathrm{h}) \\
\text { Urine Output Day } 2(\mathrm{~mL} / \mathrm{kg} / \mathrm{h})\end{array}$ & & $\begin{array}{l}1.2 \\
0.8 \\
0.8\end{array}$ & $\begin{array}{l}0.9 \\
0.5 \\
0.5\end{array}$ & & $\begin{array}{l}0.5 \\
0.4 \\
0.4\end{array}$ & $\begin{array}{l}0.7 \\
0.4 \\
0.3\end{array}$ & $\begin{array}{l}0.0001^{*} \\
<0.0001^{*} \\
0.0001^{*}\end{array}$ & & $\begin{array}{l}0.7 \\
0.6 \\
0.6\end{array}$ & $\begin{array}{l}1.1 \\
0.5 \\
0.4\end{array}$ & & $\begin{array}{l}0.4 \\
0.3 \\
0.3\end{array}$ & $\begin{array}{l}0.5 \\
0.2 \\
0.3\end{array}$ & & $\begin{array}{l}0.1 \\
0.3 \\
0.4\end{array}$ & $\begin{array}{l}0.2 \\
0.5 \\
0.1\end{array}$ & \\
\hline 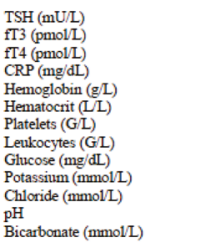 & & $\begin{array}{l}1.2 \\
4.6 \\
16.9 \\
0.3 \\
141.0 \\
0.41 \\
220.0 \\
7.4 \\
118.0 \\
4.0 \\
103.0 \\
7.38 \\
24.2\end{array}$ & $\begin{array}{l}1.1 \\
1.4 \\
4.4 \\
1.4 \\
20.0 \\
0.05 \\
79.0 \\
3.3 \\
48.0 \\
0.4 \\
5.0 \\
0.06 \\
2.3\end{array}$ & & $\begin{array}{l}1.3 \\
4.3 \\
17.8 \\
1.1 \\
134.0 \\
0.40 \\
209.5 \\
8.6 \\
126.0 \\
4.0 \\
101.0 \\
7.38 \\
24.5\end{array}$ & $\begin{array}{l}1.1 \\
1.3 \\
4.5 \\
4.1 \\
18.0 \\
0.06 \\
104.0 \\
4.5 \\
44.5 \\
0.6 \\
6.0 \\
0.07 \\
2.8\end{array}$ & $\begin{array}{l}0.4 \\
0.02^{*} \\
0.4 \\
0.0001^{*} \\
0.0003^{*} \\
0.004^{*} \\
0.06 \\
0.0001^{*} \\
0.2 \\
0.9 \\
0.0006^{*} \\
0.6 \\
0.7\end{array}$ & & $\begin{array}{l}1.3 \\
4.3 \\
18.2 \\
0.9 \\
135.0 \\
0.40 \\
204.0 \\
8.5 \\
129.5 \\
4.0 \\
102.0 \\
7.38 \\
24.7\end{array}$ & $\begin{array}{l}1.1 \\
1.2 \\
6.6 \\
3.6 \\
20.0 \\
0.06 \\
100.3 \\
4.6 \\
44.0 \\
0.5 \\
7.0 \\
0.06 \\
2.2\end{array}$ & & $\begin{array}{l}1.3 \\
3.9 \\
17.7 \\
1.3 \\
134.0 \\
0.40 \\
212.0 \\
8.6 \\
124.5 \\
4.0 \\
100.0 \\
7.39 \\
24.3\end{array}$ & $\begin{array}{l}1.1 \\
1.2 \\
5.2 \\
4.0 \\
16.5 \\
0.05 \\
88.0 \\
4.6 \\
42.5 \\
0.6 \\
6.0 \\
0.06 \\
3.0\end{array}$ & & \begin{tabular}{l|l} 
& 1.7 \\
4.1 & \\
17.5 \\
2.4 \\
130.0 \\
0.38 \\
219.0 \\
10.4 \\
115.0 \\
4.3 \\
100.5 \\
7.33 \\
22.3
\end{tabular} & $\begin{array}{l}0.9 \\
1.7 \\
3.8 \\
4.0 \\
16.0 \\
0.12 \\
171.0 \\
4.9 \\
27.0 \\
0.8 \\
6.3 \\
0.06 \\
5.8\end{array}$ & \\
\hline
\end{tabular}

The ROC curves were each computed using two variables, CysC and an additional variable CRP, TSH or BMI, respectively. Based on a two-variable logistic regression model, a linear predictor was computed, which in turn was used to serve as a score to predict the minimum AKI stage that would occur for each patient. In order to increase the AUC, the CysC, CRP, and TSH are displayed on a logarithmic scale. When comparing ROC curves with an additional variable (CRP, TSH, BMI) to ROC curves with solely CysC, no
Table 1B. Comorbidities; ACS: Acute coronary syndrome; CKD: Chronic kidney disease; MI: Myocardial infarction; PAD: Peripheral artery disease.

\begin{tabular}{|c|c|c|c|c|}
\hline & \multirow{2}{*}{$\begin{array}{c}\text { AKIN } 0 \\
n(\%)\end{array}$} & \multicolumn{3}{|l|}{ AKIN 1-3 } \\
\hline & & $n(\%)$ & $p$-value & $\begin{array}{l}\text { Total } \\
\mathrm{n}(\%)\end{array}$ \\
\hline $\begin{array}{l}\text { Comorbidities } \\
\text { - Infectious } \\
\text { - Hypertension } \\
\text { - Heart failure } \\
\text { - Diabetes } \\
\text { - Stroke } \\
\text { - CKD } \\
\text {-PAD } \\
\text {-ACSMI }\end{array}$ & $\begin{array}{l}66(27 \%) \\
127(52 \%) \\
53(22 \%) \\
52(21 \%) \\
18(7 \%) \\
23(9 \%) \\
12(5 \%) \\
47(19 \%)\end{array}$ & $\begin{array}{l}38(25 \%) \\
110(72 \%) \\
39(26 \%) \\
43(28 \%) \\
10(7 \%) \\
23(15 \%) \\
10(7 \%) \\
37(24 \%)\end{array}$ & $\begin{array}{l}0.73 \\
0.0001^{*} \\
0.39 \\
0.12 \\
0.84 \\
0.11 \\
0.50 \\
0.26\end{array}$ & $\begin{array}{l}94(24 \%) \\
237(60 \%) \\
92(23 \%) \\
95(24 \%) \\
28(7 \%) \\
46(12 \%) \\
22(6 \%) \\
84(21 \%)\end{array}$ \\
\hline
\end{tabular}

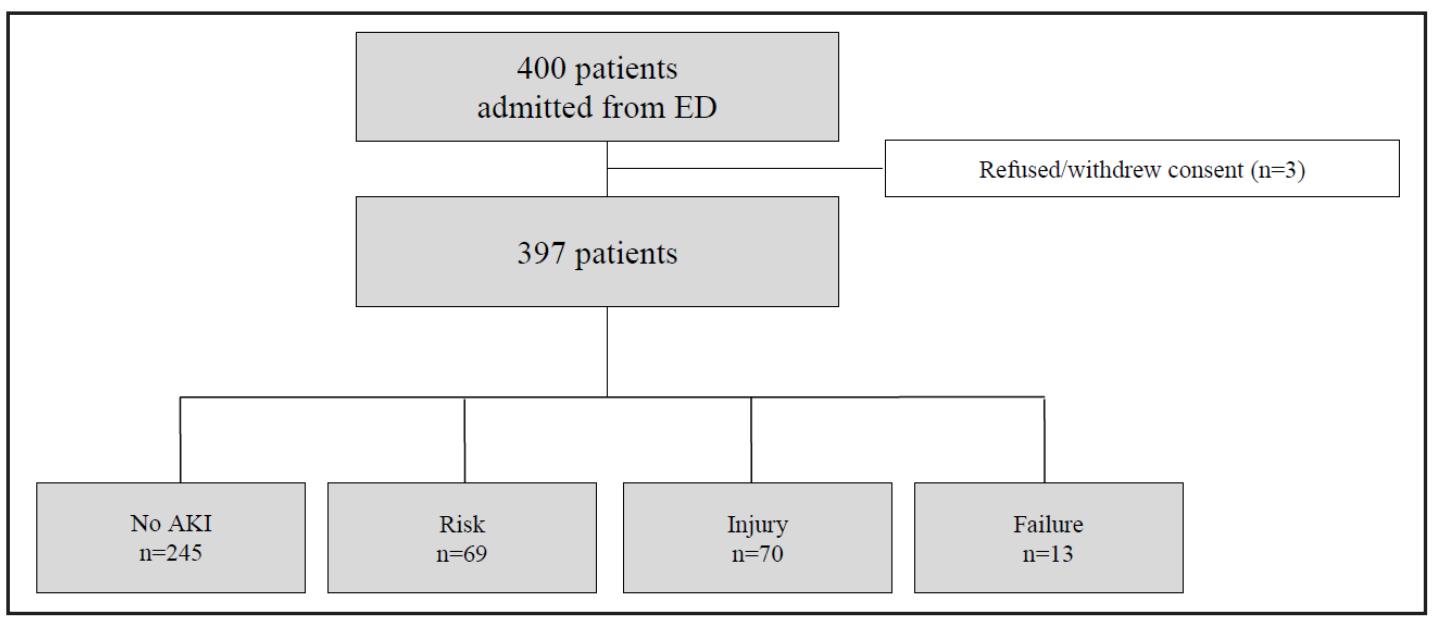

Fig. 1. Frequencies of AKI stages $(n=397)$. 


\section{Kidney \\ Blood Pressure Research}

Fig. 2. Correlation of $\mathrm{sCr}$ and CysC levels, summarized by a scatter plot smoother and Spearman's rank correlation coefficient. The AKI stage is indicated.

Fig. 3. Scatterplots of (a) CRP levels, (b) BMI and (c) TSH levels versus CysC. Besides BMI each quantity is given on a logarithmic scale. The normal range of CysC is indicated by a green bar.

$\nabla$

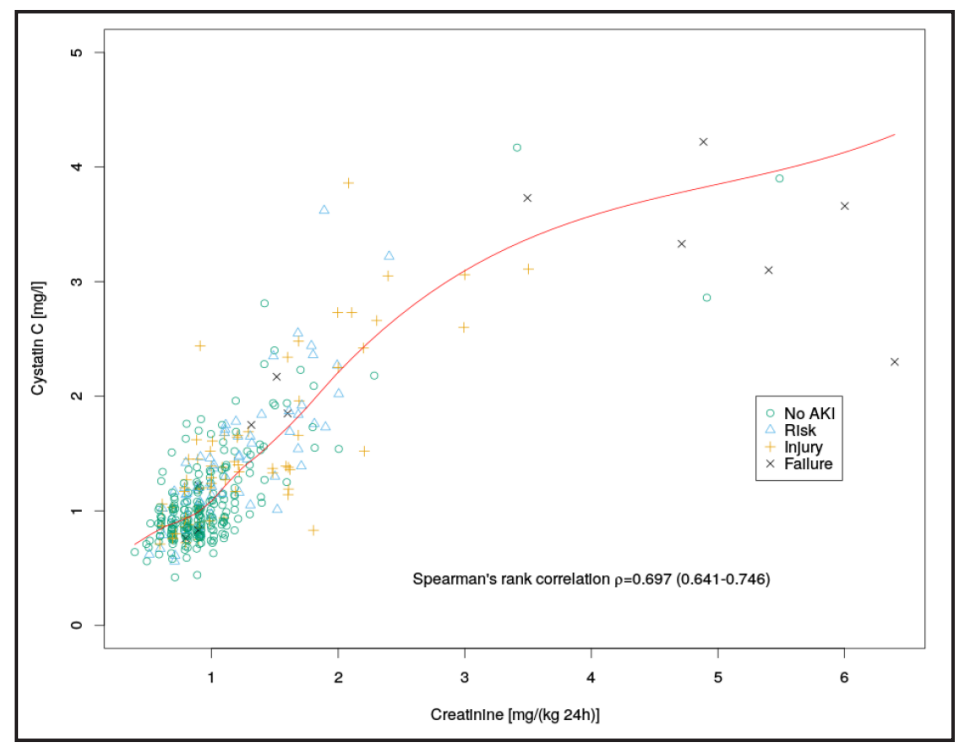

(a)

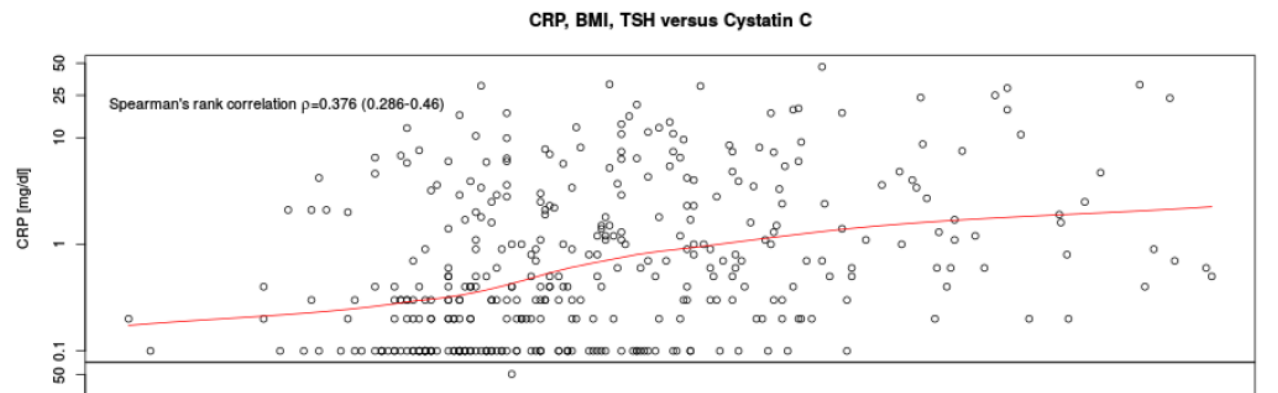

(b)

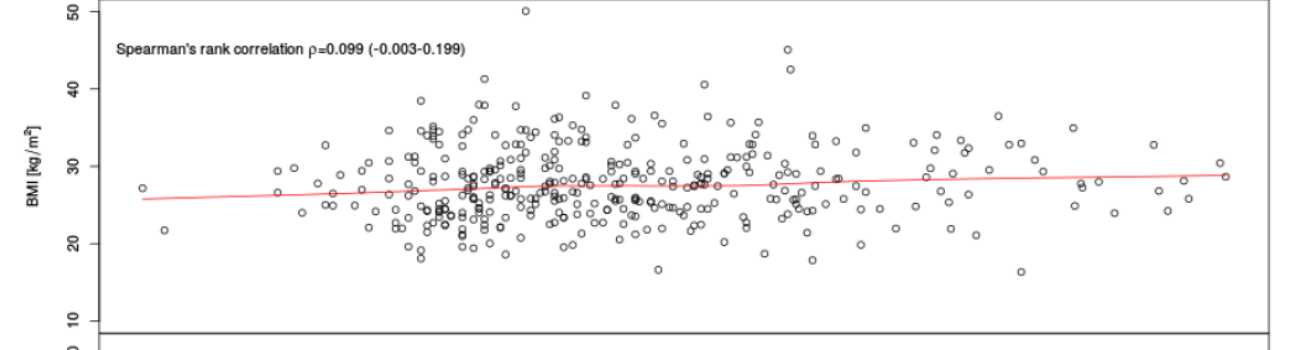

(c)

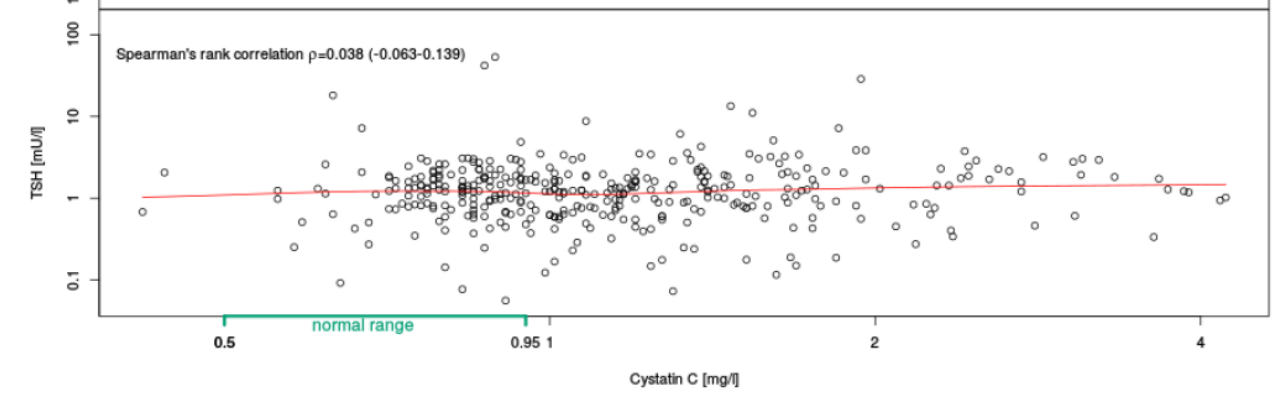

significant correlation was shown $(p>0.05)$, indicating that these factors might not have an influence on risk prediction of AKI.

Influence of Thyroid Function, Inflammation and BMI in chronic kidney disease

In an additional analysis, we investigated if our results are reproducible in the subgroup of patients with known chronic kidney disease (CKD). A correlation of CysC levels with urine albumin-to-creatinine ratio in CKD patients was described previously [22]. Due to a sample 


\section{Kidney \\ Blood Pressure \\ Research}

Kidney Blood Press Res 2016;41:604-613

\begin{tabular}{l|l}
\hline DOI: 10.1159/000447929 & (C) 2016 The Author(s). Published by S. Karger AG, Basel
\end{tabular}

Published online: September 01, 2016 www.karger.com/kbr

Schanz et al.: Cystatin C and the Role of Influencing Factors in Acute Kidney Injury

Table

Prediction of

AKI stage by

cystatin $\mathrm{C}$ and

the influence

of CRP, TSH

and BMI levels.

Variable 1:

correlation

between AKI

stage and

CysC; Variable

2: correlation

between AKI-

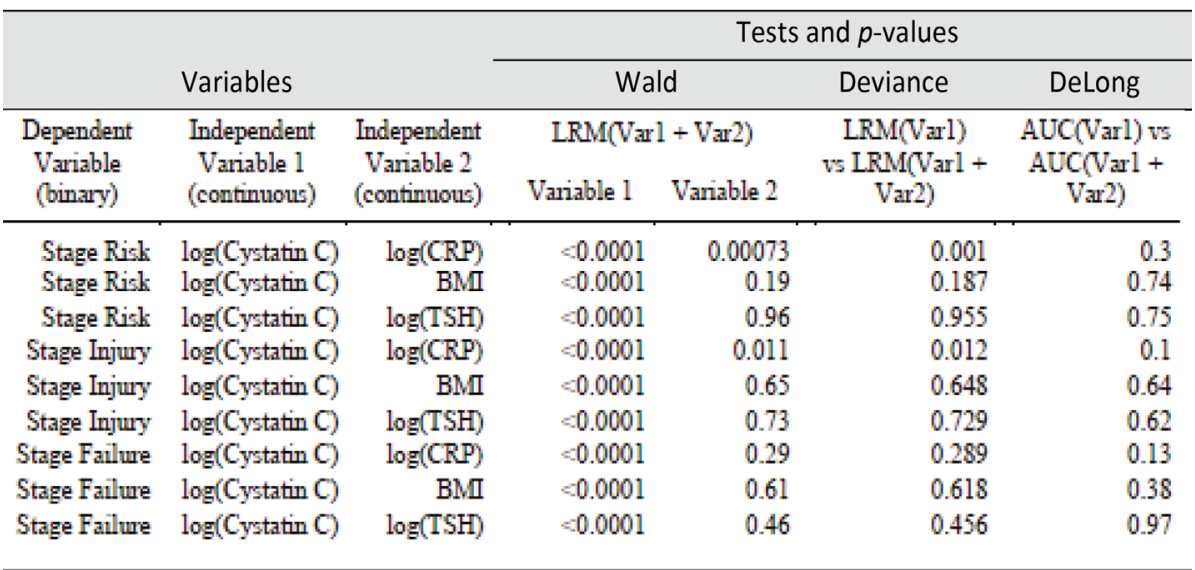

stage and CRP, TSH and BMI levels respectively. DeLong: comparison of ROC curves using two variables, cystatin $\mathrm{C}$ and an additional variable CRP, TSH or BMI, respectively. LRM: Logistic Regression Model

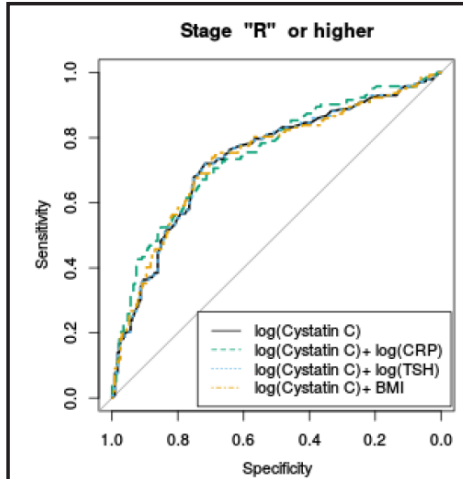

(a)

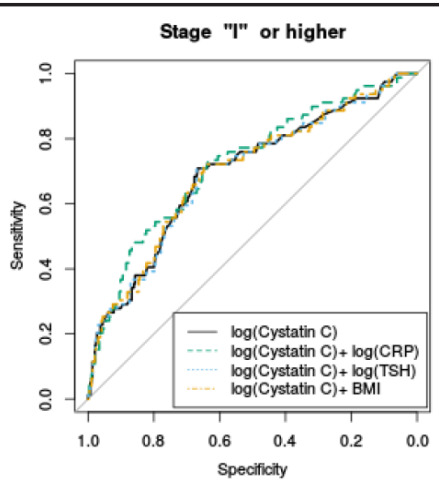

(b)

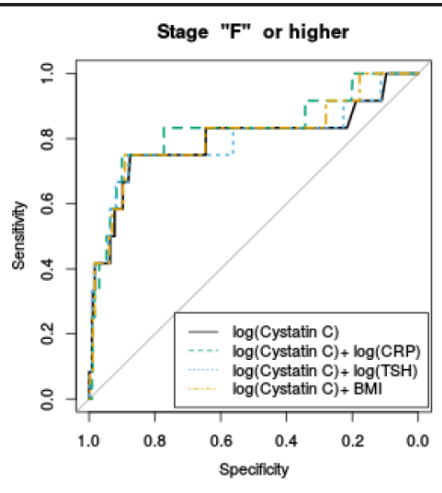

(c)

Fig. 4. Prediction of AKI-stage by CysC and the influence of CRP, TSH and BMI levels. The ROC curves were each computed using two variables, CysC and an additional variable CRP, TSH or BMI, respectively. Based on a two-variable logistic regression model, a linear predictor is computed which in turn is used to serve as a score to predict the minimum AKI stage that the patient will undergo. To increase the AUC, CysC, CRP, and TSH are taken on a logarithmic scale. Formulas given in the legends should be interpreted only as a formal description of the model used to set up the predictor. As a result, our data does not suggest that CRP, TSH or BMI improves prediction of AKI stage beyond prediction solely based on CysC levels.

size of n=1, AKI stage "F”" wasn't analyzed. No significant association between log(CRP), BMI and $\log (\mathrm{TSH})$ and AKI stages "risk" and "injury" was remarkable $(p>0.05)$ (Table 3 and Fig. 5).

\section{Discussion}

CysC is used increasingly in the assessment of AKI [23], is more closely representative of the GFR [24], and because of a putative absence of confounding through sex, age, or muscle mass, this protein is considered superior to $\mathrm{sCr}$ as a renal biomarker [25-28].

Detection of AKI in ED is a major problem in clinical practice: For accurate diagnosis of $\mathrm{AKI}$, a change in sCr or decline in urine output is necessary [2], but baseline $\mathrm{sCr}$ is mostly not 


\section{Kidney Blood Pressure Research}

Table 3. Prediction of AKI stage by cystatin $\mathrm{C}$ and the influence of CRP, TSH and BMI levels in the subgroup with chronic kidney disease $(\mathrm{n}=46)$. No data for stage " $\mathrm{F}$ " are given due to a small sample size $(\mathrm{n}=1)$. Variable 1: correlation between AKI stage and CysC; Variable 2: correlation between AKI-stage and CRP, TSH and BMI levels respectively. DeLong: comparison of ROC curves using two variables, cystatin $\mathrm{C}$ and an additional variable CRP, TSH or BMI, respectively. LRM: Logistic Regression Model

\begin{tabular}{|c|c|c|c|c|c|c|}
\hline \multicolumn{7}{|c|}{ Subgroup with chronic kidney disease } \\
\hline & & & \multicolumn{4}{|c|}{ Tests and $p$-values } \\
\hline & & & \multicolumn{2}{|c|}{ Wald } & \multirow{3}{*}{$\begin{array}{c}\text { Deviance } \\
\text { LRM(Varl) } \\
\text { vs LRM(Var1 + } \\
\text { Var2) }\end{array}$} & \multirow{3}{*}{$\begin{array}{c}\text { DeLong } \\
\text { AUC(Varl) v } \\
\text { AUC(Varl }+ \\
\text { Var } 2)\end{array}$} \\
\hline Dependent & Independent & Independent & LRM(Var & $1+\operatorname{Var} 2)$ & & \\
\hline (binsry) & (continuous) & (continuous) & Variable 1 & Variable 2 & & \\
\hline Stage Risk & $\log ($ Cystatin $C)$ & $\log (\mathrm{CRP})$ & 0.016 & 0.13 & 0.124 & 0.6 \\
\hline Stage Risk & $\log ($ Cystatin $C)$ & BMI & 0.01 & 0.16 & 0.142 & 0.98 \\
\hline Stage Risk & $\log ($ Cystatin $C)$ & $\log (\mathrm{TSH})$ & 0.0072 & 0.1 & 0.048 & 0.5 \\
\hline Stage Injury & $\log ($ Cystatin $C)$ & $\log (\mathrm{CRP})$ & 0.038 & 0.072 & 0.058 & 0.2 \\
\hline Stage Injury & $\log ($ Cystatin $C)$ & BMI & 0.021 & 0.26 & 0.254 & 0.65 \\
\hline Stage Injury & $\log (\mathrm{Cystatin} C)$ & $\log (\mathrm{TSH})$ & 0.014 & 0.12 & 0.075 & 1 \\
\hline
\end{tabular}

Fig. 5. Prediction of AKI-stage by CysC and the influence of CRP, TSH and BMI levels in the subgroup with chronic kidney disease $(n=46)$. No ROC curve for stage " $\mathrm{F}$ " is given due to a small sample size $(\mathrm{n}=1)$.

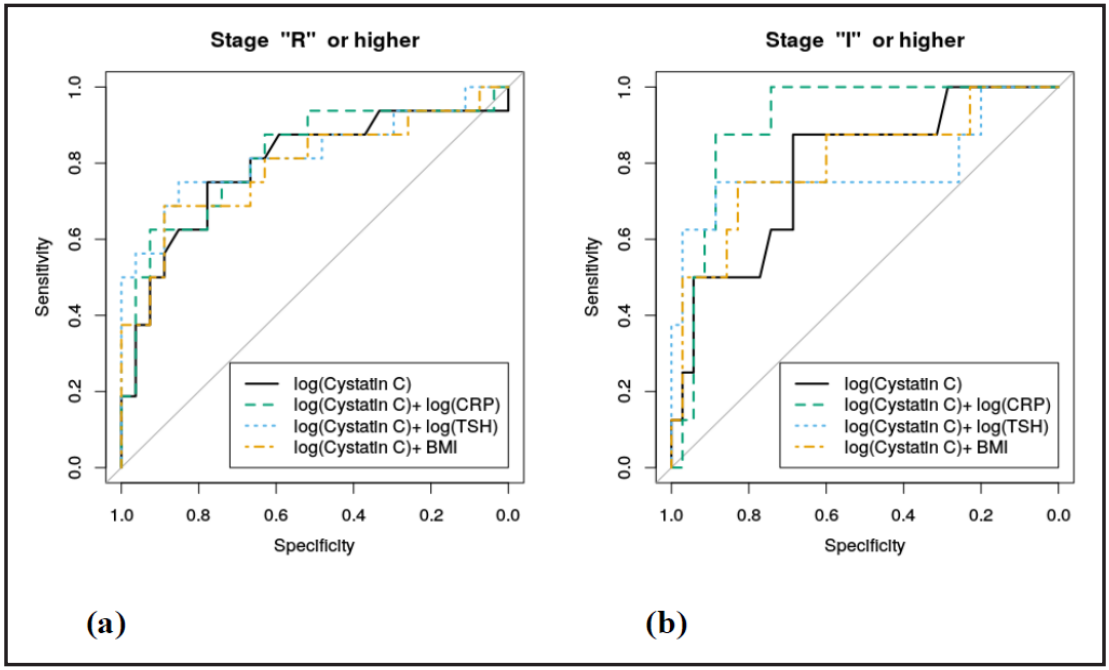

available at arrival to ED and urinary catheterization for measuring urine output is frequently not indicated. This leads to delay in AKI diagnosis and therapy which results in a poorer outcome and increased mortality rate [29]. Therefore $\mathrm{CysC}$ as a novel renal biomarker was examined in AKI: Beyond solely indicating glomerular filtration rate (GFR), CysC also seems to play a role in the prediction of AKI. In different settings, like cardiac surgery, pediatric surgery or critically-ill patients, CysC showed the ability to act as a biomarker for risk prediction of AKI [30-32].

Moreover, in the heterogeneous ED population, a single CysC measurement can give further information on kidney function. Bongiovanni et al. showed an odds ratio of 5.04 for development of AKI at CysC levels $>1.44 \mathrm{mg} / \mathrm{dl}$ at admission [33]. Furthermore, CysC was found to be superior to $\mathrm{SCr}$ as an early predictive biomarker of AKI in the ED setting [7].

Shortly after the discovery of $\mathrm{CysC}$, there was growing evidence of a variety of influences on CysC levels like inflammation (expressed as CRP level elevation), body weight and height $[17,34]$. Furthermore, we described a significant impact on CysC through thyroid function: CysC levels were significantly lower in hypo- and significantly higher in hyperthyroid patients. By showing an inverse correlation to the measured GFR, we concluded CysC might 


\section{Kidney \\ Blood Pressure Research}

be useless in patients with thyroid dysfunction [16], which was confirmed by other groups [35]. Because of this vast number of potential influences, some authors recommended avoidance of CysC for estimation of kidney function [17].

Our goal was to investigate the relevance of these influences and their impact on diagnostic accuracy for detecting AKI in the ED. To our knowledge, so far no study has examined the influences of thyroid function, BMI, and CRP on CysC in the ED setting.

In our ED cohort we proved the known positive correlation of CRP and CysC. Higher CysC levels were found in cases of elevated CRP levels, in accordance with previous studies [17]. But one might wonder if these influences are relevant in clinical practice for risk prediction of AKI, especially in heterogeneous patient populations such as in the ED.

When comparing the ROC curves for prediction of AKI, no significant differences were detected between CysC solely and CysC in combination with BMI, CRP, and TSH respectively (Fig. 4). According to our results, the mentioned influences have no impact on diagnostic accuracy and therefore no relevance in clinical practice for risk prediction of AKI. The same observation was made by Wang et al. in critical ill patients in ICU [36]. Because CysC is a renal filtration marker we tested in an additional analysis these influence in the subgroup of patients with chronic kidney disease and could not find any influence.

Despite a variety of influences on CysC levels, our data suggest that these factors have no impact on ROC curves and the usage of CysC in risk prediction of AKI in ED seems to be appropriate in clinical practice.

\section{Conclusion}

In summary, despite several known influences on CysC level, like thyroid function, CRP and BMI, our data indicates that these factors have no impact on diagnostic accuracy for risk prediction of AKI - this implies that no relevant influence is evident on CysC readings in clinical practice. Consequently, it seems appropriate to measure CysC in ED patients for risk prediction of AKI.

\section{Abbreviations}

ADQI: Acute dialysis quality initiative; AKI: Acute kidney injury; AUC: Area under the receiver operating characteristics curve; CKD: Chronic kidney disease; CysC: Cystatin C; CRP: C-reactive protein; ED: Emergency department; sCr: Serum creatinine; GFR: Glomerular filtration rate; KDIGO: Kidney Disease: Improving Global Outcomes; KDOQI: Kidney Disease Outcomes Quality Initiative; BMI: Body mass index; TSH: Thyroid stimulating hormone; T3: Triiodothyronine; T4: Thyroxine; TIMP2: TIMP metallopeptidase inhibitor 2; IGFBP7: Insulin-like growth factor-binding protein 7.

\section{Disclosure Statement}

M. Kimmel received lecture honoraria by Abbott, Roche and Astute Medical. M.D. Alscher received lecture honoraria by Abbott and Roche.

\section{Acknowledgments}

This study was supported by the Robert-Bosch Foundation (Stuttgart, Germany). We thank our study nurses, A. Schwab and B. Rettenmaier for their support. 


\section{Kidney \\ Blood Pressure Research}

\section{References}

1 Hsu RK, McCulloch CE, Dudley RA, Lo LJ, Hsu CY: Temporal changes in incidence of dialysis-requiring AKI. J Am Soc Nephrol 2013;24:37-42.

2 Kidney Disease: Improving Global Outcomes (KDIGO) Acute Kidney Injury Work Group: KDIGO Clinical Practice Guideline for Acute Kidney Injury. Kidney Int Suppl 2012;1-138.

3 Chertow GM, Burdick E, Honour M, Bonventre JV, Bates DW: Acute kidney injury, mortality, length of stay, and costs in hospitalized patients. J Am Soc Nephrol 2005;16:3365-3370.

4 Coca SG, Singanamala S, Parikh CR: Chronic kidney disease after acute kidney injury: a systematic review and meta-analysis. Kidney Int 2012;81:442-448.

5 Lameire NH, Bagga A, Cruz D, De Maeseneer J, Endre Z, Kellum JA, Liu KD, Mehta RL, Pannu N, Van Biesen W, Vanholder R: Acute kidney injury: an increasing global concern. Lancet 2013;382:170-179.

6 Schuur JD, Venkatesh AK: The growing role of emergency departments in hospital admissions. N Engl J Med 2012;367:391-393.

7 Soto K, Coelho S, Rodrigues B, Martins H, Frade F, Lopes S, Cunha L, Papoila AL, Devarajan P: Cystatin C as a marker of acute kidney injury in the emergency department. Clin J Am Soc Nephrol 2010;5:1745-1754.

8 Soto K, Papoila AL, Coelho S, Bennett M, Ma Q, Rodrigues B, Fidalgo P, Frade F, Devarajan P: Plasma NGAL for the diagnosis of AKI in patients admitted from the emergency department setting. Clin J Am Soc Nephrol 2013;8:2053-2063.

9 Di Somma S, Magrini L, De Berardinis B, Marino R, Ferri E, Moscatelli P, Ballarino P, Carpinteri G, Noto P, Gliozzo B, Paladino L, Di Stasio E: Additive value of blood neutrophil gelatinase-associated lipocalin to clinical judgement in acute kidney injury diagnosis and mortality prediction in patients hospitalized from the emergency department. Crit Care 2013;17:R29.

10 Challiner R, Ritchie JP, Fullwood C, Loughnan P, Hutchison AJ: Incidence and consequence of acute kidney injury in unselected emergency admissions to a large acute UK hospital trust. BMC Nephrol 2014;15:84.

11 Nickolas TL, O'Rourke MJ, Yang J, Sise ME, Canetta PA, Barasch N, Buchen C, Khan F, Mori K, Giglio J, Devarajan P, Barasch J: Sensitivity and specificity of a single emergency department measurement of urinary neutrophil gelatinase-associated lipocalin for diagnosing acute kidney injury. Ann Intern Med 2008;148:810-819.

12 Nickolas TL, Schmidt-Ott KM, Canetta P, Forster C, Singer E, Sise M, Elger A, Maarouf O, Sola-Del Valle DA, O'Rourke M, Sherman E, Lee P, Geara A, Imus P, Guddati A, Polland A, Rahman W, Elitok S, Malik N, Giglio J, El-Sayegh S, Devarajan P, Hebbar S, Saggi SJ, Hahn B, Kettritz R, Luft FC, Barasch J: Diagnostic and prognostic stratification in the emergency department using urinary biomarkers of nephron damage: a multicenter prospective cohort study. J Am Coll Cardiol 2012;59:246-255.

13 Kellum JA, Sileanu FE, Murugan R, Lucko N, Shaw AD, Clermont G: Classifying AKI by Urine Output versus Serum Creatinine Level. J Am Soc Nephrol 2015;26:2231-2238.

14 Tenstad O, Roald AB, Grubb A, Aukland K: Renal handling of radiolabelled human cystatin C in the rat. Scand J Clin Lab Invest 1996;56:409-414.

15 Abrahamson M, Olafsson I, Palsdottir A, Ulvsback M, Lundwall A, Jensson O, Grubb A: Structure and expression of the human cystatin C gene. Biochem J 1990;268:287-294.

16 Kimmel M, Braun N, Alscher MD: Influence of thyroid function on different kidney function tests. Kidney Blood Press Res 2012;35:9-17.

17 Knight EL, Verhave JC, Spiegelman D, Hillege HL, de Zeeuw D, Curhan GC, de Jong PE: Factors influencing serum cystatin $\mathrm{C}$ levels other than renal function and the impact on renal function measurement. Kidney Int 2004;65:1416-1421.

18 Kimmel M, Shi J, Latus J, Wasser C, Kitterer D, Braun N, Alscher MD: Association of renal stress/damage and filtration biomarkers with subsequent AKI during hospitalization among patients presenting to the emergency department. Clin J Am Soc Nephrol 2016;11:938-946.

19 Ricci Z, Cruz DN, Ronco C: Classification and staging of acute kidney injury: beyond the RIFLE and AKIN criteria. Nat Rev Nephrol 2011;7:201-208.

20 DeLong ER, DeLong DM, Clarke-Pearson DL: Comparing the areas under two or more correlated receiver operating characteristic curves: a nonparametric approach. Biometrics 1988;44:837-845. 


\section{Kidney \\ Blood Pressure Research}

21 R Development Core Team: R: A language and environment for statistical computing. R Foundation for Statistical Computing, Vienna, Austria 2008.

22 Ekart R, Bevc S, Hojs N, Knehtl M, Dvoršak B, Hojs R: Albuminuria is Associated With Subendocardial Viability Ratio in Chronic Kidney Disease Patients. Kidney Blood Press Res 2015;40:565-574.

23 Herget-Rosenthal S, Marggraf G, Husing J, Goring F, Pietruck F, Janssen O, Philipp T, Kribben A: Early detection of acute renal failure by serum cystatin C. Kidney Int 2004;66:1115-1122.

24 Dharnidharka VR, Kwon C, Stevens G: Serum cystatin C is superior to serum creatinine as a marker of kidney function: a meta-analysis. Am J Kidney Dis 2002;40:221-226.

25 Vinge E, Lindergard B, Nilsson-Ehle P, Grubb A: Relationships among serum cystatin C, serum creatinine, lean tissue mass and glomerular filtration rate in healthy adults. Scand J Clin Lab Invest 1999;59:587-592.

26 Finney H, Newman DJ, Price CP: Adult reference ranges for serum cystatin C, creatinine and predicted creatinine clearance. Ann Clin Biochem 2000;37:49-59.

27 Finney H, Newman DJ, Thakkar H, Fell JM, Price CP: Reference ranges for plasma cystatin C and creatinine measurements in premature infants, neonates, and older children. Arch Dis Child 2000;82:71-75.

28 Norlund L, Fex G, Lanke J, Von Schenck H, Nilsson JE, Leksell H, Grubb A: Reference intervals for the glomerular filtration rate and cell-proliferation markers: serum cystatin $\mathrm{C}$ and serum beta 2-microglobulin/cystatin C-ratio. Scand J Clin Lab Invest 1997;57:463-470.

29 Joslin J, Ostermann M: Care of the critically ill emergency department patient with acute kidney injury. Emerg Med Int 2012;2012:760623.

30 Zhang J, Denton BT, Balasubramanian H, Shah ND, Inman BA: Optimization of PSA screening policies: a comparison of the patient and societal perspectives. Med Decis Making 2012;32:337-349.

31 Delanaye P, Lambermont B, Chapelle JP, Gielen J, Gerard P, Rorive G: Plasmatic cystatin C for the estimation of glomerular filtration rate in intensive care units. Intensive Care Med 2004;30:980-983.

32 Arun O, Celik G, Oc B, Unlu A, Celik JB, Oc M, Duman A: Renal effects of coronary artery bypass graft surgery in diabetic and non-diabetic patients: a study with urinary neutrophil gelatinase-associated lipocalin and serum cystatin C. Kidney Blood Press Res 2015;40:141-152.

33 Bongiovanni C, Magrini L, Salerno G, Gori CS, Cardelli P, Hur M, Buggi M, Di Somma S: Serum Cystatin C for the Diagnosis of Acute Kidney Injury in Patients Admitted in the Emergency Department. Dis Markers 2015;2015:416059.

34 Marmarinos A, Garoufi A, Panagoulia A, Dimou S, Drakatos A, Paraskakis I, Gourgiotis D: Cystatin-C levels in healthy children and adolescents: Influence of age, gender, body mass index and blood pressure. Clin Biochem 2016;49:150-153.

35 Ye Y, Gai X, Xie H, Jiao L, Zhang S: Impact of thyroid function on serum cystatin C and estimated glomerular filtration rate: a cross-sectional study. Endocr Pract 2013;19:397-403.

36 Wang F, Pan W, Wang H, Zhou Y, Wang S, Pan S: The impacts of thyroid function on the diagnostic accuracy of cystatin C to detect acute kidney injury in ICU patients: a prospective, observational study. Crit Care 2014;18:R9. 